This is a self-archived version of an original article. This version may differ from the original in pagination and typographic details.

Author(s): Jakonen, Teppo

Title: The integration of content and language in students' task answer production in the bilingual classroom

Year: 2019

Version: Accepted version (Final draft)

Copyright: @ 2019 Informa UK Limited, trading as Taylor \& Francis Group

Rights: In Copyright

Rights url: http://rightsstatements.org/page/InC/1.0/?language=en

Please cite the original version:

Jakonen, T. (2019). The integration of content and language in students' task answer production in the bilingual classroom. International Journal of Bilingual Education and Bilingualism, 22(4), 428-444. https://doi.org/10.1080/13670050.2016.1267694 
The integration of content and language in students' task answer production in the bilingual classroom

Teppo Jakonen

Centre for Applied Language Studies, University of Jyväskylä, Finland

Accepted for publication in International Journal of Bilingual Education and

Bilingualism 


\title{
The integration of content and language in students' task answer production in the bilingual classroom
}

\author{
The notion of content and language integration has recently become a key topic \\ of inquiry in research on Content and Language Integrated Learning (CLIL) and \\ other kinds of bilingual educational programmes. Understanding what integration \\ is and how it happens is of fundamental importance not only for researchers \\ interested in gauging the possibilities and limitations of bilingual programmes, \\ but also for practitioners seeking optimal ways to support student development. \\ This study investigates integration as it takes place in the context of collaborative \\ writing in the classroom. Drawing on Conversation Analytic (CA) methodology, \\ text production is investigated as a social and sequentially-evolving phenomenon. \\ The analysis focuses ons interactional sequences through which secondary school \\ students produce and revise written task answer formulations. Sequential \\ analyses of selected interactions describe the interactional organisation of the \\ focal practice and show how, in their negotiation about what and how to write, \\ students integrate content and language in everyday school work. It is argued that \\ an investigation of what is at stake to students when they produce texts can shed \\ light on their practical orientations to content and language integration. Based on \\ such perspectives, integration appears a more complex phenomenon than the \\ interface of form and meaning.
}

Keywords: content and language integration; CLIL; conversation analysis (CA); peer interaction; writing

\section{Introduction}

A central task for teachers, students and policymakers in different kinds of bilingual programmes is to manage two types of interfaces: the content-language relationship and the oral-written continuum (Esquinca 2011; Hornberger and Skilton-Sylvester 2000). In these programmes, it is not enough that students learn target language, as the programmes also have simultaneous learning objectives related to content knowledge in subjects such as history, geography, and so on. This also means that in order to efficiently support a balanced development of content and language skills, it is crucial 
to conceptualise what exactly their relationship is, how they are (or are not) integrated in different areas of educational planning and implementation, i.e., in the policies, curricula and actual micro-level classroom practices of bilingual education. Content and language integration is also a highly relevant concern in processes and practices of classroom writing, as the theoretical notions of subject-specific or disciplinary literacies attest.

In this paper, I investigate these two concerns - integration and writing - as they play out in the social practices of collaborative task work between peers in a Content and Language Integrated Classroom (CLIL). Despite a long awareness that writing is not only an individual skill but also a process and practice, situated in a particular context that plays an important role for text production, in educational contexts writing is still relatively rarely studied as a phenomenon that happens in and through social interaction. The present study addresses this gap by exploring from a conversation analytic (CA) perspective how students interactionally produce, revise and negotiate linguistic formulations for written task answers during group activities. Producing task answer formulations is not only a recognisable literacy practice in the life of many classrooms, but it is also an activity during which concerns about content and language as well as their relationship become relevant for teachers and students. By focusing analytical attention on what students orient to as 'adequate' or 'correct' when they formulate answers and - perhaps even more importantly - revise such formulations, the analyst can begin to trace how students integrate language and content in the praxis of bilingual education. In other words, these practices of collaborative writing provide a window into learner perspectives on content and language integration. This study will show that, and how, students can attend to various local and contextual relevancies in 
text production, thereby treating integration as a more complex phenomenon than the mapping of linguistic form against meaning.

\section{Content and Language Integration in Bilingual Education}

While much of earlier research on bilingual educational programmes such as CLIL has focused on language learning outcomes or processes, recent literature has begun to shift the attention on content, and to problematize the notions of and relationship between 'content' and 'language' (Barwell 2005a; Gajo 2007; Llinares 2015; Nikula, Dafouz, et al. 2016). Although content and language integration is clearly a fundamental concern for programmes like CLIL - as its name already implies - it is considerably difficult to pin down what integration is and to investigate how it happens. As Nikula, Dafouz, et al. $(2016,2)$ point out, even the phrase content and language integration can (inadvertently) suggest that language and content would be somehow separate entities. Indeed, full separation represents a theoretical standpoint that would not likely receive much support among educational linguists, many of whom would instead see the relationship between linguistic form and academic knowledge as deeply interrelated, much like in the functional tradition (see e.g. Schleppegrell 2004).

In the broader literature of content-based approaches to language teaching, integration is often seen as an instructional matter that requires the teacher to direct student attention on linguistic form, either proactively or reactively in response to learner errors. This can, for instance, be done as part of 'counterbalanced instruction' whereby student attention is systematically oriented to "the direction opposite to that which their classroom environment has accustomed them' (Lyster 2007, 4), a 'focus on form' (FonF) approach that involves brief attention to problematic language during communicative activities, or a predetermined, structural 'focus on forms' (FonFS) instruction (see Loewen 2011). While such approaches may give the impression that 
content and language integration is a relatively straightforward matter of instructional planning, it is useful to remember that even the notion of 'linguistic form' can cover a broad range of phenomena: a recent definition by Nassaji and Fotos $(2011,13)$ includes 'grammatical, phonological, lexical and pragmatic' components of language. Moreover, in the light of research on academic language (Achugar and Carpenter 2014; Schleppegrell and O'Hallaron 2011) and subject-specific or disciplinary literacies (Meyer et al. 2015; Nikula 2012; Shanahan and Shanahan 2008), content and language integration extends beyond single language forms to also concern discourses that are longer than written sentences or interactional turns.

All in all, recent research on content and language interface in bilingual education has foregrounded its multidimensional nature. For example, Nikula, Dafouz, et al. (2016) identify three distinct dimensions, or perspectives to integration: these are curricular planning and pedagogies, participants' perceptions and beliefs, and actual classroom practices (see also Barwell 2005b). Broadly speaking, this paper addresses the last of these sites of content and language integration by investigating integration as it takes place during the production of L2 writing in peer interaction in the CLIL classroom.

\section{L2 Writing in and as Social Interaction during Task Activities}

Writing represents a topic that has been and that continues to be explored within a wide range of research traditions. Many such traditions have recently witnessed a shift from analysing finished texts, 'products' and 'outcomes', towards broadening the focus on both the individual processes and social practices through which texts are produced. In prior classroom-based literature, students' collaborative writing in L2 has been prominently investigated through a sociocultural lens. Much of this literature (for an overview, see Storch 2011) builds on the notions of 'languaging' and 'language-related 
episodes' (LREs), i.e., situations in which learners use language to make meaning and construct knowledge (Swain 2006, 98). Prominent among this research strand is the work by Neomy Storch, whose early study (Storch 1997) investigated the resources used by adult ESL learners engaged in editing talk. She found that they drew on their intuition (e.g. by repeating phrases a few times to note how they sound), grammar knowledge (e.g. by citing or alluding to some grammatical rule), clues from the surrounding text, as well as general or personal knowledge about the topic area.

In contrast to the subsequent sociocultural work that has often taken a quantitative or experimental approach to investigate how variables such as task type relate to the frequency of LREs in learner talk (e.g. de la Colina and García Mayo 2007; Kim 2009), the present study is more descriptive in its orientation and investigates writing as a social, sequentially-evolving interactional phenomenon that takes place in the context of a distinct literacy practice. Such a perspective connects this study to the emerging studies in ethnomethodological (EM) and conversation analytic (CA) literature that explore writing as a social, embodied and interactional activity (for introduction, see Mondada and Svinhufvud 2016).

While the intersection of writing and talk in bilingual classrooms remains a largely understudied area, prior CA studies have shown some typical interactional practices through which writing gets produced in these contexts. For example, Lerner (1995) has shown that the formulation of a stand-alone task answer (i.e. an answer that can be written down) entails that students construct an utterance which is markedly disengaged from its sequential and interactional environment. His study described how bilingual third-grade students produced such written answers in response to reading comprehension tasks by using a practice taught by their teacher. This practice, 'echoing the question in the answer' (124), used the very formulation of the task as a resource for 
the production of an answer. Thus, a reading comprehension question such as 'What is Grizzle grumbling about?' could be made into the beginning of a stand-alone answer 'Grizzle is grumbling about...'. Lerner (1995) showed how the conversational actions of search initiation, production of a candidate completion to the answer beginning, and the acceptance or rejection of the candidate completion are key elements in the interactional organisation of the practice. However, even if the particular practice was originally designed to help students to write, it was not entirely waterproof: one typical trouble that students encountered, as described by Lerner (1995), was that they mispaired types of questions with answer beginnings, which eventually led them to answer 'wrong' questions.

The ways in which answers to group tasks are produced in and through peer talk was also the focus of Szymanski's (2003) study, which built on and extended the work by Lerner (1995). Szymanski showed that the formulation of written answers in fact consists of two interactional sub-activities, which are 'question-answering' and 'answer-framing'. Question-answering is about coming up with a substantive answer to the question 'as one would do in ordinary conversation', in addition to which students still face the task of making their answer fit the 'written grammatical frame' of the task (533). In addition, Szymanski (2003) described how answer-framing can be done via three distinct methods of reiterating the interrogative words in the question (much like Lerner [1995] suggested), by locating words in the question that could work as the beginning of a possible answer, or by 'sounding out' strings of words until a suitable answer is reached. Interestingly, the two activities described by Szymanski (2003) can also be thought of in terms of content and language integration. It is not difficult to see question-answering as having to do with establishing the content knowledge of a task 
answer and answer-framing as ensuring that the formulation of that content represents a linguistically and stylistically appropriate task response.

Peer interaction for the purposes of text production can also have a distinctly bilingual organisation, as was shown by Cromdal's (2005) study of collaborative text production at a computer. In his data, Swedish-speaking students enrolled in an Englishmedium secondary school displayed a systematic division of labour between L1 and L2. The students used English to formulate text to be written down or to quote elements of their text-in-progress, and Swedish for any other kind of negotiation that the process of writing involved, e.g., for expressing agreement or disagreement as well as for directing each other. Cromdal (2005) argued that such locally negotiated language alternation supported the students' writing process by allowing them to recognise which of their actions were directly related to text production. Cromdal's (2005) findings are also highly pertinent to the current discussion on the use of L1 in bilingual education (see e.g. Gierlinger, 2015; Jakonen 2016b; Méndez García \& Pavón Vázquez, 2012) in that they provide micro-interactional evidence of systematics of L1 use in support of learning.

As students get older, the role of writing in the classroom becomes more complex than is perhaps the case with written exercises that are completed with a few 'simple' words. One such context is found in university language classes, in which writing may also be a way of planning for spoken language use. A study by Kunitz (2015) investigated situations where students planned for a future classroom presentation by producing scriptlines - objects that remind them what to say in the eventual presentation - which they collaboratively shaped in interaction and wrote down as scaffolding artefacts for the oral presentation. Kunitz's (2015) study showed that writing and formulating what to write are central aspects of these kinds of planning 
tasks. It also shed light on the intricate interrelatedness of talk and text, as well as the complexity of the oral-written continuum (Esquinca 2011), when students talk to construct text that serves the purpose of supporting their L2 talk in the future.

All in all, prior CA studies of writing in diverse bilingual classrooms have demonstrated that text production within pedagogical activities can be a highly social and interactional process. In these situations, talk is deeply intertwined with available texts, which have both material and semiotic dimensions, being artefacts that are physically handled and otherwise oriented to (Jakonen 2015). While talk routinely serves the purposes of coming up with things to write down and coordinating the writing activity, writing itself can also be carried out to support talk. In both kinds of activities, talk and texts-in-progress have a reflexive, local relevance to each other. This relevance is also familiar for those analysing classroom activities in which texts are handled, in the form of a difficulty in establishing what some stretch of talk is about if one does not have access to same texts as the participants. Addressing the relationship between talk and text can therefore also be seen as a fundamental prerequisite for understanding functions of L2 talk in bilingual classrooms.

The present study addresses this understudied literacy interface where classroom texts, talk and writing come together. It examines the practical work done by students as they jointly formulate written task answers in CLIL peer interaction. In CLIL and other bilingual classrooms, there is a pressure for such task answers to be not only linguistically but also content-wise 'correct' and 'adequate', which means that the very production of answer formulations is a literacy activity in which content and language become integrated by students in ways that are meaningful to them. By looking at how students observably display and orient to concerns of adequacy, correctness and relevance while they formulate and revise task answers during collaborative writing, the 
study seeks to complement prior literature on integration in bilingual education (Gajo 2007; Llinares 2015; Nikula, Dafouz, et al. 2016) with a learner perspective. Adopting a CA approach to investigate writing as a sequentially-evolving and interactionally constructed phenomenon, the analysis focuses on students' local and situated negotiation that immediately precedes the writing down of a task answer. For research interested in the social foundations of writing, such situations offer a window into bilingual students' literacy practices, how they mediate between oracy and literacy, and how they interactionally organise collaborative text production.

\section{Data and Method}

For the empirical analysis, this study draws on a corpus of 16 video-recorded CLIL lessons on British history (each 55 minutes). These lessons were taught to native Finnish students (aged 14-15 yrs.) at a lower secondary school between December 2010 and February 2011, as part of the school's bilingual study programme. The programme could be characterised as fairly small-scale CLIL instruction, involving a relatively flexible teaching of some curricular content in English depending on the willingness and competences of current staff members. At the time of data collection, the teacher who participated in this study was the only one in the school who taught academic content in English, and her two history lessons per week were the only CLIL lessons which the recorded participants had. The teacher, an experienced content specialist, was a native Finnish speaker who was fluent in English and had previously worked abroad. While the official language policy of the classroom was to use English in all communication, in actual practice this was limited to teacher-student interaction, whereas the students used both Finnish and English for task work. Importantly, however, all learning materials were in English, which was also the language in which the students were expected to complete their written assignments. 
The collected data include recordings of peer interaction as well as all textual artefacts that participants handled and produced in interaction, i.e., course readings, task sheets and students' notebooks. Having all these data is crucial for the analytical attempt to reconstruct the process of collaborative writing in peer groups: when these different data are considered together, the analyst can get a sense of the local and contextual aspects of the students' work to formulate answers as one can see what they are referring to in interaction.

The data extracts analysed in this paper come from a collection of interactions (37 altogether) in which students collaboratively formulate and/or revise a task answer. These interactions took place during various types of reading and writing tasks, both when students were working in groups so that a group either shared a task sheet or each student worked independently on their own sheet but they were allowed to cooperate in order to complete the task. The analysis of selected cases draws on ethnomethodological conversation analysis, CA, (Sidnell and Stivers 2012; ten Have 2007). The data has been transcribed following the Jefferson (2004) notation conventions (see Appendix), so that the transcripts integrate images of the writing tasks that the students were working on in the situation. While the course readings were an integral part of students' work to formulate answers, being texts that students repeatedly refer to, they are not reproduced in transcripts. Instead, the course readings are briefly referred to in the analysis when they are relevant for understanding the situation shown in transcripts. ${ }^{1}$ Furthermore, turns that contain Finnish language units have been translated into English, aiming at a

\footnotetext{
${ }^{1}$ The course readings are not directly reproduced in the article because they contain copyrighted material. However, they are available upon request from the author.
} 
translation that attempts to preserve the turn's (grammatical) structure as much as possible. To protect students' identities, all names in transcripts are pseudonyms.

\section{Integration of Content and Language in Task Answer Production}

The analysis focuses on CLIL students' negotiation to formulate and revise written answers during task work. Such negotiation quite routinely precedes (but can also overlap with) the beginning to write down an answer during group tasks, in which students typically share a task sheet. However, collaboration for and talk about answer formulations is not limited to group work, as the present analysis will show. It is a salient aspect of students' coordination of independent task work in task designs where they are to produce answers in their own notebooks or on individual task sheets. In these situations, students have multiple ways to turn task-answering into a joint interactional activity, for example, by requesting from each other what they have already written down (see also Jakonen 2016a).

The extracts shown here describe diverse routes that students take to produce written answers, each of which treats content and language and their relation slightly differently. As a general observation on the present data, it should be noted that the kinds of criteria that adequate task answers need to fulfil, as oriented to by students in the focal sequences, are quite complex and go beyond 'language' in the sense of grammatical and stylistic correctness. Students may also orient to the importance of getting the 'content' right, so that the subject-specific knowledge that they describe in the answer is in line with the available classroom materials. Beyond these concerns, answers will also need to satisfy local and contextual requirements that deal with how the current learning task is framed - such as when quiz questions designed by students need to be to be 'suitably difficult' for the intended audience. 
The analysis is organised in two sections. The first section describes how proposals for task answers are immediately accepted and thereby treated as sufficient for the purposes of the task by their peers. It serves to illustrate some recurrent features of the interactional organisation of task-answering. After that the analysis will discuss more elaborate cases where students revise a proposed formulation. For the analyst, these provide information about content and language integration in that they show what aspects of a formulation students treat as insufficient and how they go about reviewing them.

\section{Proposing and Accepting Answer Formulations}

The first extract shows a straightforward instance of proposing and accepting an answer formulation. In the extract, a group of three students is completing a task that involves designing quiz questions based on a history text, to be later presented to the rest of the class. The group has been given a sheet on which the teacher has pre-selected interrogative words as question beginnings which the groups need to complete. These particular students have already been working on the task for a while when Aulikki, who is also responsible for writing down the group's answers, proposes a continuation to a question beginning with 'what'.

\section{Extract 1. Proposing an L2 formulation.}

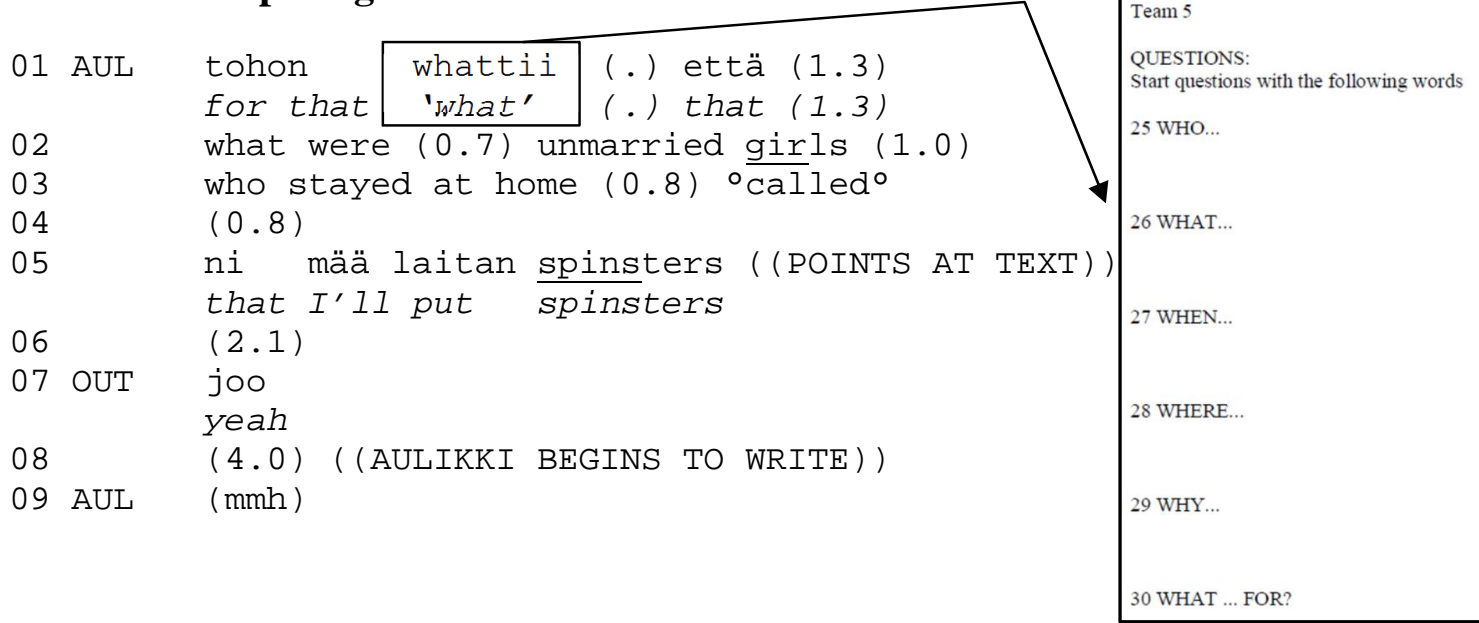


Over the nine lines of this extract, the students formulate an answer to a task item and begin to write it down in their task sheet. Looking at Aulikki's turn at lines 1-3 in more detail, it is possible to see some key elements of which the action of proposing an answer consists. Firstly, at line 1, she announces a specific task item on the sheet (question beginning with 'what') and indicates that she will propose a candidate formulation. One consequence of multi-item task sheets is that when groups of students are filling them in, they will have to coordinate which item they are referring to. While these tasks may have a numerical order, it is not uncommon that students skip some items or do them in a different order, for example by tackling 'easy ones' first.

Next, Aulikki produces the answer formulation itself (lines 2-3) and thereby makes it available to her peers' consideration. Notice also that as Aulikki, after a 0.8 silence, provides an answer to the quiz question that she has just formulated, she at the same time points at the source text. This can be seen as a demonstration of the correctness of the formulation, a warrant that makes visible the grounds for the answer and proves that it is possible and even sensible within the boundaries set by the source text. This information concerning 'spinsters' is in fact not 'put' down on the task sheet at any point; instead, it constitutes the eventual answer to the group's question, which other students eventually have to know in the quiz.

Even if it might seem that Aulikki produces the particular formulation on her own, the social nature of group work is oriented to by way of organising the answer production as a distinct proposal sequence. This can be seen in how Aulikki begins to write the formulation down (line 8) only after she has received a token of acceptance from Outi (line 7). Thus, besides the interactional nature of writing, extract 1 also shows how the relationship of content and language can be treated as 'unproblematic' as students go about their task. Furthermore, they employ a clear division of bilingual 
resources in the answer formulation so that they use their L1 except when uttering the answer-to-be-written-down (lines 2-3) or when quoting items from the source text (line 5), similar to what Cromdal (2005) has described.

In addition to proposing a 'final' answer formulation, the substantive content that makes up a task answer can also be made available to others in L1 (cf. the activity of 'question-answering' in Szymanski 2003). A typical way of doing this entails that the proposer identifies information in the source text and explains (in L1) how that information is relevant for the answer, including how it could be used in the actual answer formulation. In such cases, the use of L1 provides a signal that the formulation itself needs more work. This is also the case in the next extract, in which Jere, Inka and Sakari are interacting to complete individual tasks on the Stuart period. In the extract, Jere asks Inka for an answer formulation for a task asking what the cure for smallpox was during those days. As he instead receives an L1 explanation of the 'content' for a possible answer, he uses it to formulate an answer in L2.

\section{Extract 2. Establishing a formulation through L1 explanation of 'content'.}

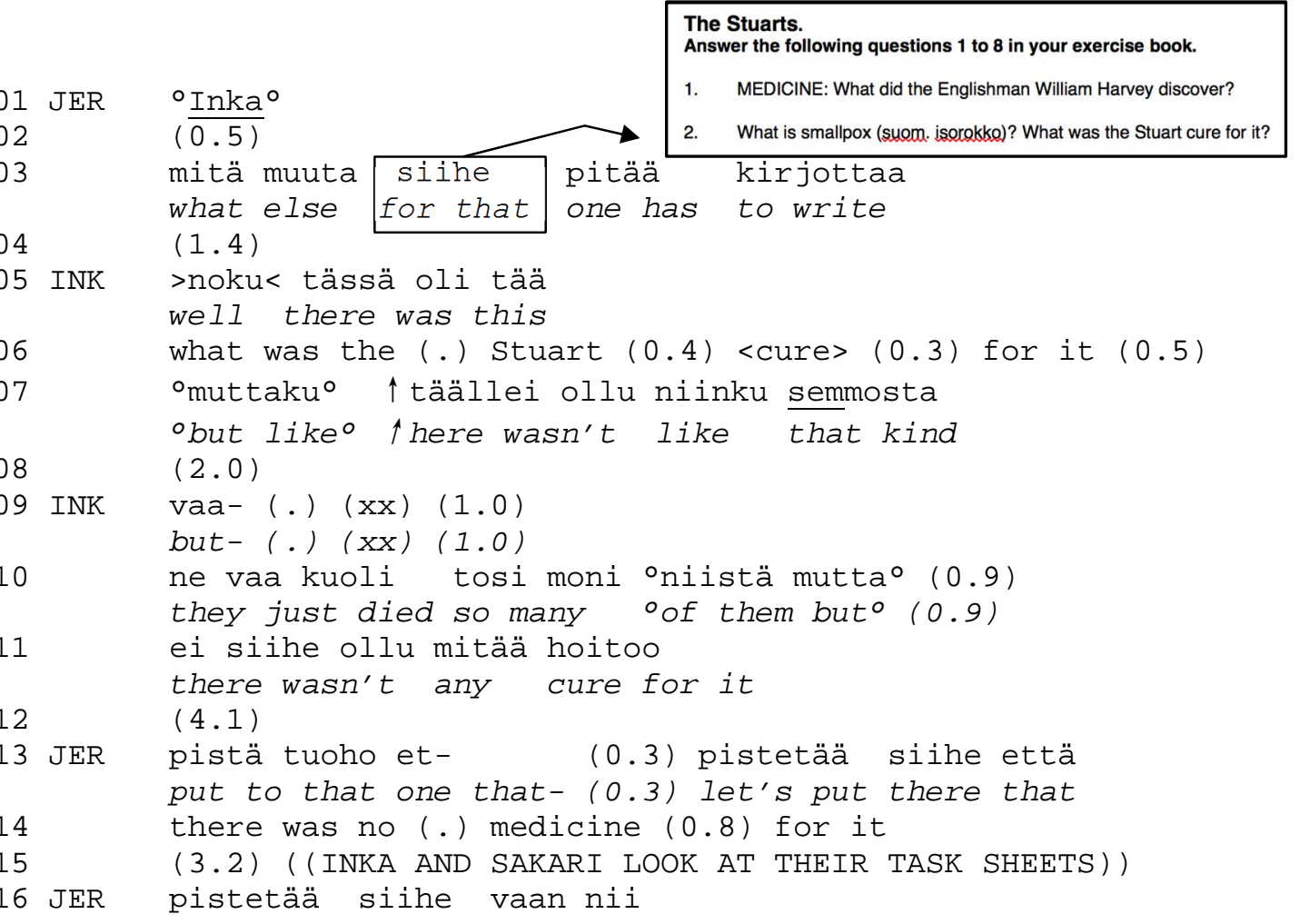




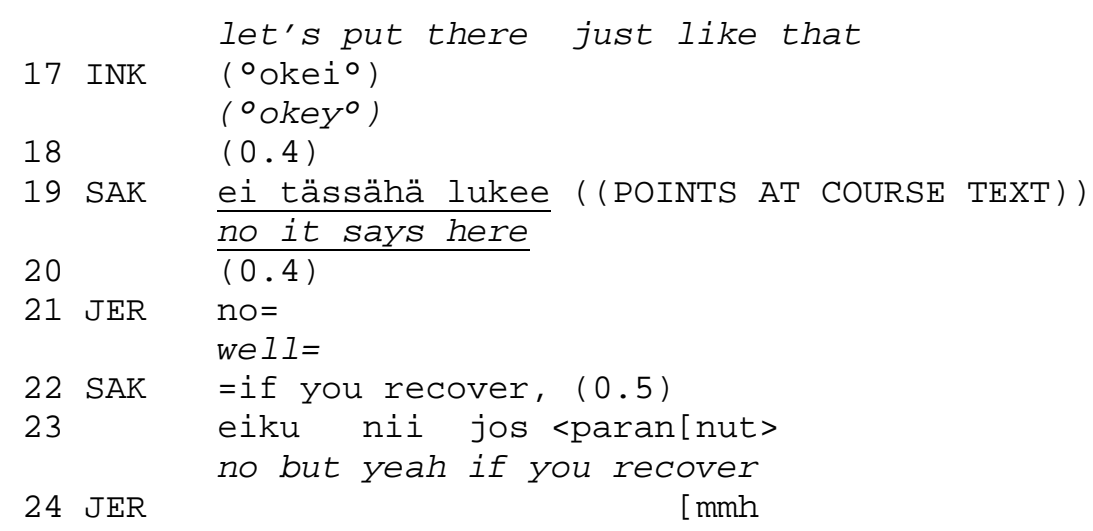

Prior to the extract, the students have completed together the first part of the particular question. Jere's request for 'what else' they need to write (line 3) orients to this as of yet incompleteness of their answer. The design of Jere's request does not so much project an invitation to collaboratively produce an answer formulation in the here-and-now as it does request Inka to share her individual answer with him (see also Jakonen 2016a).

Inka's response does not provide the invited straightforward formulation. Instead, she accounts for its non-provision by reading aloud the part of the task that still needs answering (lines 5-6) and by reporting a problem in finding information that would answer such a question (line 7). As Jere (like other group members) refrains from taking a turn during the two-second silence, Inka continues to explicate her understanding of the source text. For these students, the problem that prevents an answer from being formulated is that the text details no 'cure' against smallpox (line 11). Jere's solution, which he presents after a few seconds of due consideration, is to turn Inka's problem into the answer by translating it almost directly to L2, a practice that in fact bears similarities to 'echoing the question in the answer' described by Lerner (1995). Notice also how Jere presents the answer formulation by first issuing a directive to Inka at line 13, but quickly self-repairs it into a proposition that suggests an L2 formulation for the use of the whole group.

The relevant place for others to comment on Jere's proposition would be at line 15. However, as no uptake is forthcoming (while both Inka and Sakari are examining 
their texts) he re-does the act of proposing but without repeating the prior formulation. On this occasion, Jere's proposal to write vaan nii ('just like that') can be seen as an appeal for others to settle for the simplest solution to the problem of finding no information, done to pursue the acceptance of his proposal.

The proposal is eventually accepted by Inka at line 17, just before Sakari 'notices' (see also Kääntä 2014) a part of the source text that might after all be relevant for the answer and that again puts the acceptance on hold. Once Sakari has Jere's attention, he begins to quote from the text (line 22). His continuing intonation projects continuation beyond 'recover', but instead, he provides an L1 translation of the passage, prefacing that with the particles eiku ('no but') and nii ('yeah'). As a repair initiator, eiku can mark the just-prior action as abandoned (see Laakso and Sorjonen 2010), framing here the L1 translation as a sudden realisation that the identified piece of text in fact deals with 'recovering' from smallpox and does not after all specify a cure against it. In this way, Sakari's L1 translation accomplishes the withdrawal of a competing formulation, which line 19 has projected, and ratifies Jere's proposal.

In summary, the extract shows how an L1 explanation of the 'content' of a text works as a resource for the formulation of a task answer. To the students of the extract, such 'content' for an answer and its L2 answer formulation are distinct objects, between which they mediate as they make sense of the source text and work to come up with a written answer. It takes a joint effort to transform an understanding of what the text tells into a task answer, the validity of which can in turn be checked against the source text. Interestingly, the words 'cure' (in the task instruction) and 'medicine' (in the students' answer formulation) mean slightly different things, which may play a role in the difficulty in 'finding' an answer in the source text. The text does actually provide information of a 'cure', insofar as it describes how children were subjected to a kind of 
rudimentary vaccination by being taken to visit sick people. However, this does not perhaps amount to something quite as scientific as 'medicine', which is the word that the students take as the starting point in formulating their answer.

\section{Revising a Proposed Task Answer Formulation}

As Extract 2 already suggested, proposed formulations may sometimes need to be revised before (or even after) they are written down. This section investigates some reasons and interactional practices for such revision work. Next extract shows how students can modify the language of a proposed formulation in order to make their answer stylistically more appropriate for the specific task genre. The extract features

Outi, Aulikki and Liisa completing the same set of quiz questions as in Extract 1, with Aulikki again writing down the group's answers.

\section{Extract 3. Revising the style of a formulation.}

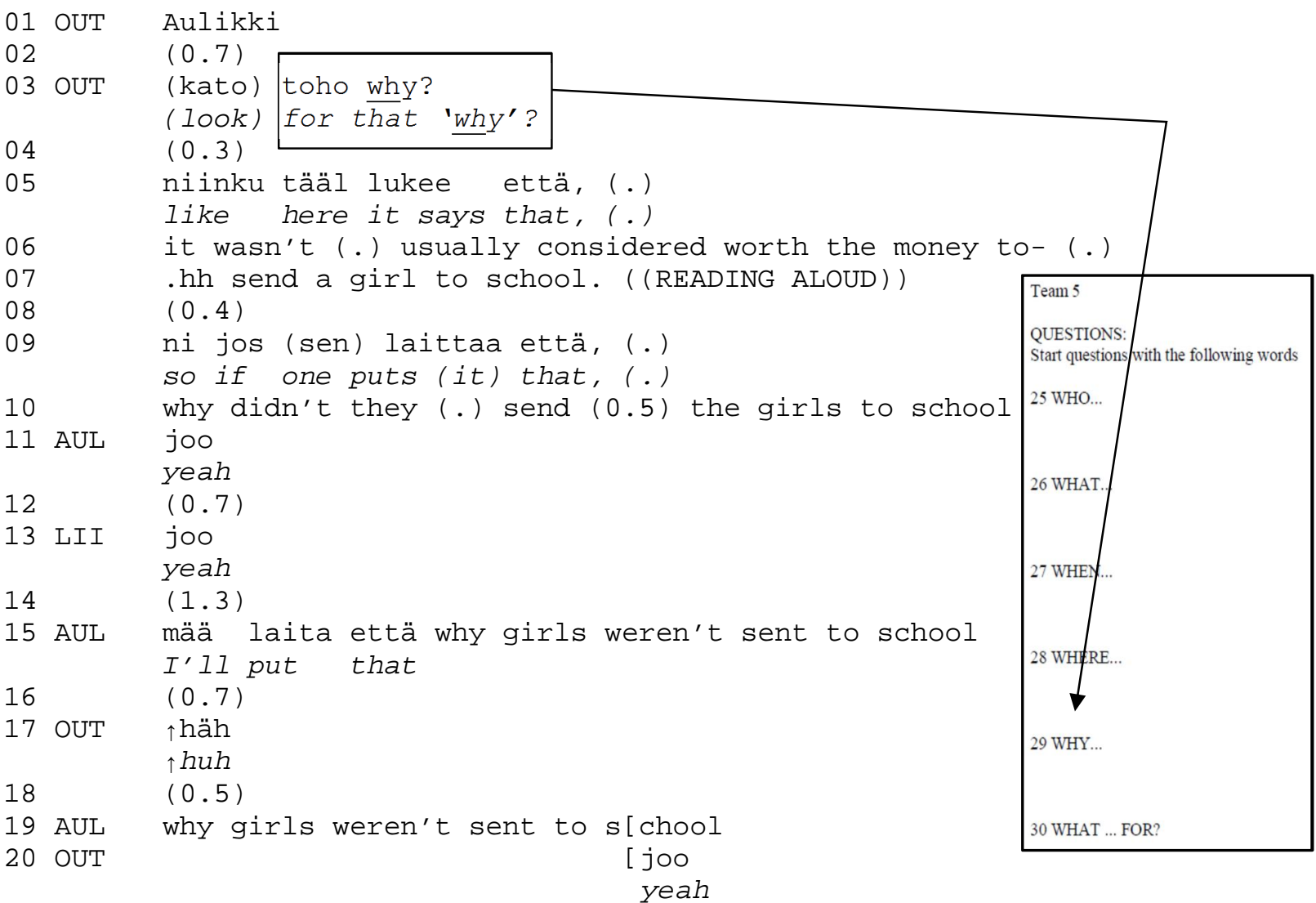

A noticeable feature of this extract is Outi's extensive framing of her answer 
formulation over lines 1-9. Similarly to what happened in Extract 1, she first indicates which task item she is targeting (question beginning with 'why'). She then makes the source text relevant for the specific task item by directing the others' attention on (line 5) and then reading aloud a part of the source text (lines 6-7). On the basis of the justread text, she then announces (line 9) and provides (line 10) a candidate formulation. Through these actions, Outi makes both a task answer and the reasoning leading to such an answer available to her peers, subjecting it to their approval.

While Outi's proposal is accepted by the other group members (lines 11 and 13), it is edited before Aulikki notes it down. Notice that Aulikki does not begin to write the proposal down immediately as Outi has formulated it, but she instead provides an account that makes a counter-proposal, a suggestion for a slightly different formulation. This modification changes the voice of the written question from active to passive, and can be seen to give it a more neutral and academic feel. And while Aulikki's action at line 15 is not grammatically designed as a proposal subject to negotiation, it is indeed treated as such, which becomes evident in how Outi provides an acceptance token at line 20, following a round of repair.

Task answer formulations are not only modified for concerns of correctness or style. The next extract, which shows another group working on a different set of quiz questions, illustrates how task-specific concerns for what is a locally suitable formulation can go beyond linguistic correctness or style to include considerations of what kind of formulation is appropriately difficult for other students. In the extract, Riku and Konsta revise a question which their group member, who is now absent, has written down in the previous lesson. This involves changing the word 'pursuit' in a question that deals with Henry VIII. 


\section{Extract 4. Revising the difficulty of a formulation.}

01 RIK err we should- $(0.4)$

02 .hh (1.0) err (1.0) a <little> change this

$03(0.4)$. hh cos maybe $n-\overline{(0.5)}$ not many knows that $\downarrow<$ word>

$04 \quad(0.9)$

05 KON <ye: :ah>

06 RIK

what were, $(2.0)$

(0.4) .hh Henry's favourite (.) hobbies

$\mathrm{m}-$ maybe $=$

=it's the same, (.) [I think

2. What Wos Henry's pursuit, alongside
rageing war and henting ?

I don't think anyone knows that, [(.) word=

=in that (.) ${ }^{\circ}$ sentence ${ }^{\circ}$

Riku indicates a need to modify the group's formulation through a multi-unit turn over lines $1-3$. He achieves what is a fairly delicate task of revising somebody other's work (even if the person who has written the original answer is not present) by pointing out that the required modification is a minor one (line 2 ) and by stating a reason for why the current formulation is problematic (line 3). The reason, which is presented through the softening effect of the word 'maybe', deals with the perceived difficultness of the word 'pursuit' for the audience: in other words, there is a need to use the kind of language in the formulation that their peers, who will be presented with the quiz question, can be expected to understand it.

After Konsta has aligned with the need for revision (line 5), Riku proposes an alternative formulation at line 6 . Konsta's response, which he provides after 2.0 seconds of consideration, is not an unqualified acceptance. Riku also orients to this by persuading Konsta a bit more: he adds at line 9 a claim that what he has proposed is 'the same', a further endorsement for the interchangeability of the words 'pursuit' and 'hobbies'. Konsta agrees with this and, after a while, reiterates Riku's prior assessment of the difficulty of 'pursuit'. Notice that this second assessment by Konsta (line 12) upgrades the one by Riku at line 3 ('not many knows' -> 'I don't think anyone knows'). 
Task answer formulations may also need revision when a particular formulation does not describe the focal content well enough according to the participants. This is the case in the last example, which shows two students, Paavali and Jouni, revising a quiz question that deals with football in the Tudor days. As they revise Jouni's answer proposal a number of times, they not only address problems of ambiguity in the answer formulation, but also work on their understanding of the source text by discussing how their answer ought to be formulated so that it would adequately reflect that understanding. The complete revision work is shown in Extracts 5 and 6, which take place some minutes apart. In Extract 5, the problem addressed by the students is a wording of the answer that may leave room for misinterpretation.

\section{Extract 5. Addressing ambiguity in an answer formulation (Football, part I).}

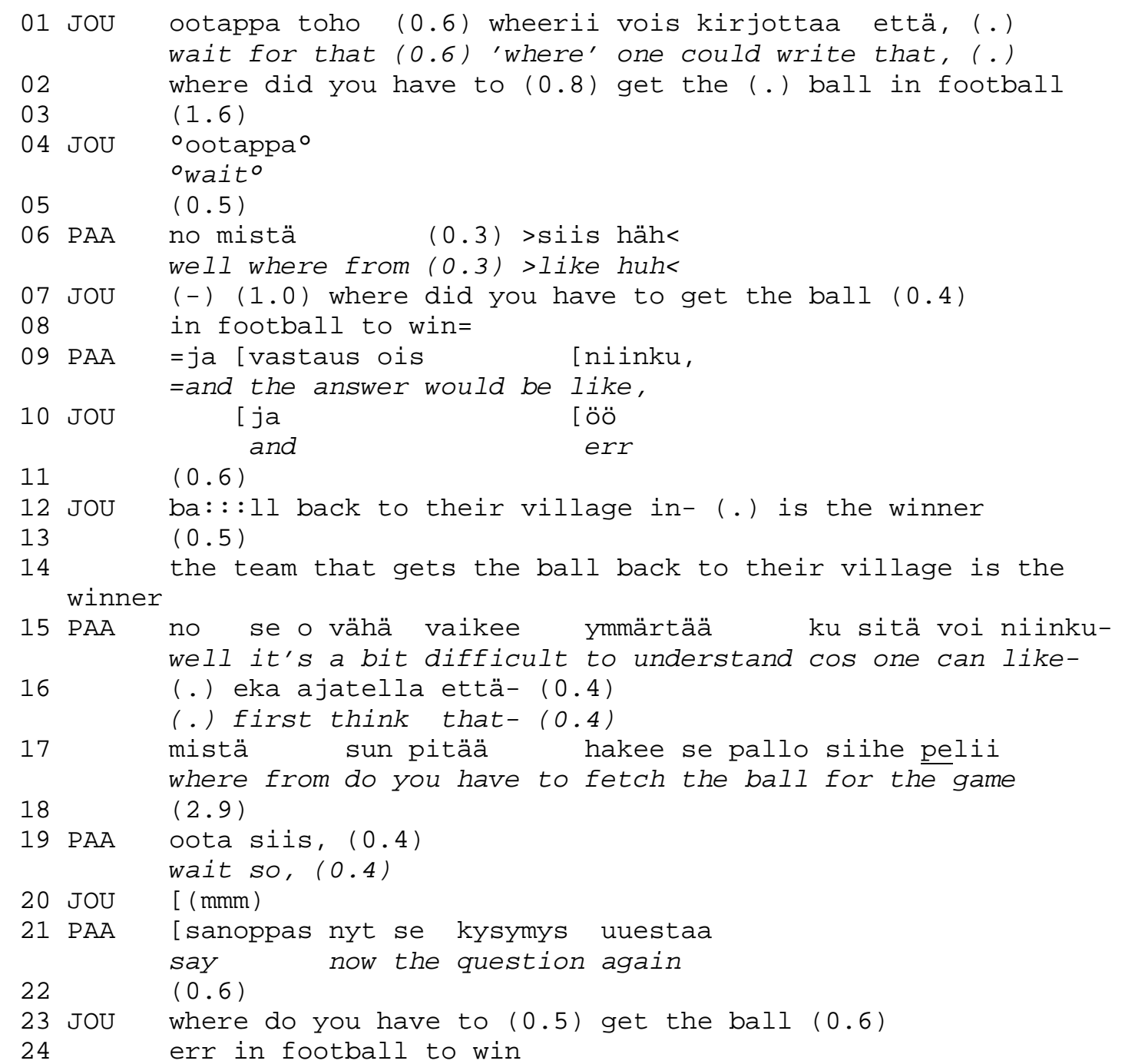




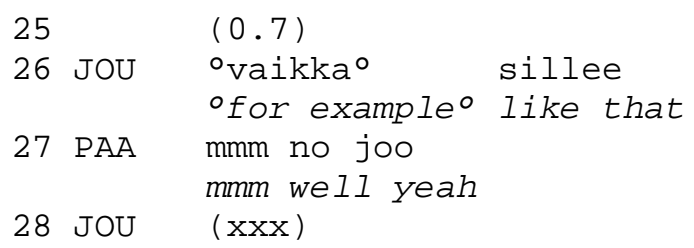

At lines 1-2, Jouni identifies the task item and announces a candidate formulation for a quiz question, 'Where did you have to get the ball in football?'. The formulation does not receive an immediate acceptance, and Jouni's request for putting the situation on hold (line 4), which he provides after a lengthy silence, already projects that the formulation needs further modification. Notice that as Paavali initiates repair at line 6, he first asks for a warrant for the formulation's correctness - i.e., what would be the answer to Jouni's formulation for a quiz question. He then utters what could be termed as an 'open' class repair (Drew 1997), siis häh ('like huh'). As he does this, he displays that he treats the question that Jouni has formulated as a question of where from, not where to.

As Jouni reformulates the question at lines 7-8, he addresses this ambiguity by adding 'to win' at the end of the candidate question. This unit aims to make it clear that the question deals with where the ball needs to be moved to while in play, not where it ought to be retrieved from prior to a game. Latching his turn immediately after the revised formulation, Paavali continues to pursue an answer to the quiz question at line 10 , yet again treating its display as a demonstration that the question has been formulated correctly. Jouni's response is to read aloud a passage of the source text that deals with early football rules (lines 12 and 14).

Having been provided a part of the course readings to justify the formulation, Paavali reiterates the critique that the question is ambiguous over lines $15-17$. By claiming that the question can be 'difficult to understand' because one can 'first think' it differently from what Jouni in fact means, he indicates a need for further revision of the 
formulation. However, as Jouni makes no attempt to reformulate during the lengthy silence at line 18, Paavali prompts him to repeat his formulation once more (lines 19, 21). The repeated formulation receives no immediate acceptance, and it is only when Jouni adds a comment that treats his own formulation as one that is at best sufficient (line 26) that Paavali accepts it in a manner which is considerably less than enthusiastic (line 27).

Extract 6 shows how the two students continue to revise their provisional formulation after having worked on other task items for some time, with Jouni proposing yet another alternative formulation. In the ensuing interaction, the two students end up working on their understanding of the content described in the source text.

\section{Extract 6. Checking the source text against a formulation (Football part II).}

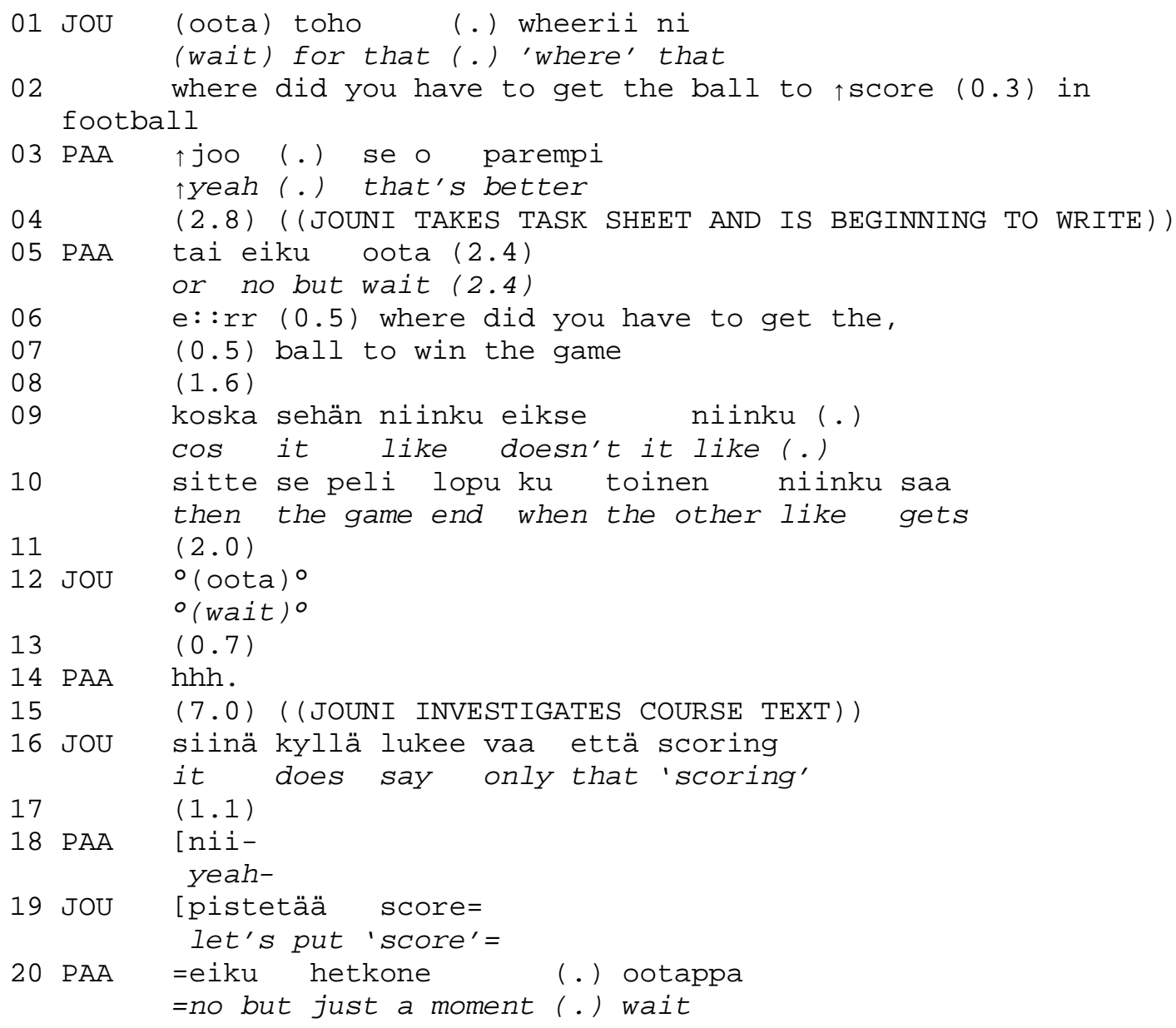




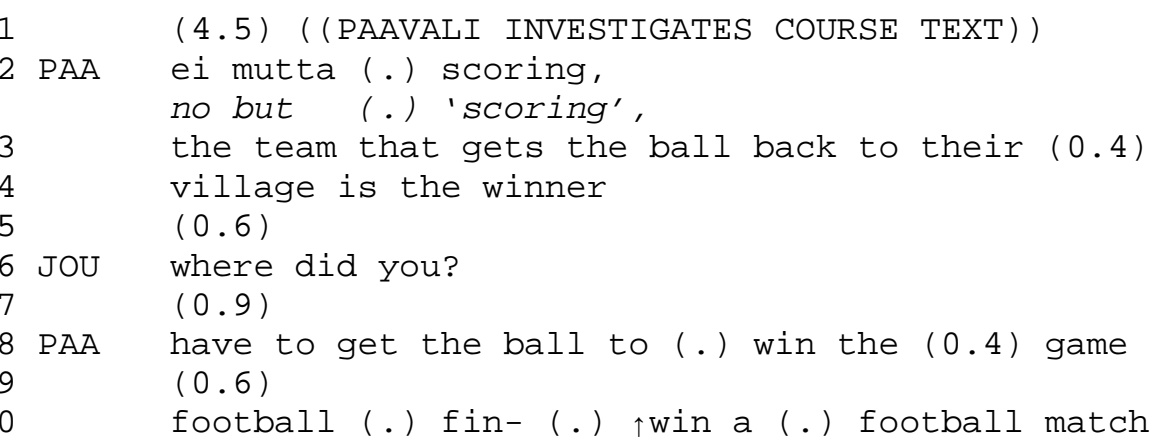

Over lines 1-2, Jouni announces the task item and presents a new formulation for a quiz question. The revised version not only has a more specified target, the emphatically stressed 'to score' (line 2), compared to his previous attempt (left unmentioned at line 2 of Extract 5). This suggestion gets an immediate, appreciating response from Paavali at line 3, which Jouni treats as strong enough agreement that the formulation can now be written down on the group's task sheet. However, as he is preparing for writing, Paavali once again puts the situation on hold (line 5) and proposes a competing formulation (lines 6-7). This version shifts the question's target to winning a match, not merely scoring in the course of a match. As Jouni does not take a stance on the formulation during the silence at line 8 , Paavali explicates his understanding of the source text (lines 9-10): the game ends when a goal is scored. Notice that Paavali's turn includes a subtle, yet important, shift in the claim to knowing what the text says as he repairs his turn syntax from declarative (koska sehän niinku, 'cos it like') to interrogative (eikse niinku, 'doesn't it like'). This shift subjects Paavali's text interpretation, not only the answer formulation, to Jouni’s acceptance.

As Jouni examines the text during the 7.0 second silence, he counters Paavali's proposal by claiming that it does not talk about 'winning', only 'scoring' (line 16), which he further suggests that they note down (line 19). It takes another request from Paavali to delay writing and the read-aloud of the part of the source text that mentions 'winning' at lines 22-24 (incidentally, one that Jouni himself read aloud in Extract 5) to 
get his proposal on the students' task sheet. Note that Jouni's response turn at line 26 is not treated as a request for showing the relevant text. Instead, it is the beginning of a formulation, which requests Paavali to dictate the rest so that it can be written down. Paavali displays this by continuing the formulation (line 28) syntactically where Jouni has left off, eventually correcting the formulation once more at line 30 . This modification involves changing the word 'game' into a more specific 'football match'.

In summary, extracts 5 and 6 show how students' work for formulating a task answer closely relates to other task activities, such as checking the source text and addressing issues of text comprehension. Even if written classroom tasks like these may appear as relatively mundane exercises, which are done by merely searching through a text to locate parts in it that are relevant for an answer, extracts 5 and 6 show that they can provide to students an interactional space for 'taking on' and problematizing content. For the two students in these extracts, the concerns are a) that their final formulation is unambiguous as for the content it targets, and b) that they do get the content 'right', in the sense of what the source text 'says'. These orientations motivate their interaction and, in turn, show the interrelatedness and the reflexive nature of language and content in their work to come up with a written formulation. When particular wordings for the task answer carry specific content-related meanings, changing one will change the other.

\section{Concluding Discussion}

This study set out to investigate how content and language become integrated as students in a CLIL classroom interactionally negotiate to formulate written task answers. Adding to the previous work by Lerner (1995) and Szymanski (2003) in particular, the present sequential analysis of selected peer interactions has shown some central activities in the production of answer formulations. These include announcing a 
candidate formulation, providing evidence that it is 'correctly' or 'sensibly' formulated in the light of local criteria set by the task, and negotiating agreement on the proposed formulation, possible through revising it. While these recurrent activities organise the interactional practice of task answer writing, the paper has also demonstrated that within their boundaries, student groups can problematize different aspects of a proposed formulation. As a result, the 'routes' that they take to come up with a written answer can be quite diverse, and in each of them, the integration of content and language plays out slightly differently. For analysts of L2 writing, this work of integration only becomes visible when students' local and interactional work for formulating and revising texts is examined, in other words, when writing is investigated as a (social) process.

In many ways, the analysed peer interactions show how writing takes place at the interface of texts and talk. Task answers get done in and through practices where coming up with an answer formulation is inextricably linked with literacy activities around other texts, such as skimming through course readings to find information for an answer, quoting materials from them for the purposes of answer formulation, and so on. In this context, students routinely treat their course readings as a source text, a material and semiotic resource that can validate (content-related) correctness by either warranting or disproving an answer formulation. This is the case both when students read aloud, point at or quote passages of the readings in an unprompted manner, either before they announce a candidate answer formulation (extracts 2 and 3 ) or directly related to it (extract 1). Similar relevance of the source text is in play when a student proposing an answer formulation does not demonstrate the relation of the formulation to the source text, and the other party pursues such a proof (extract 5). In both types of situations, what matters to students is what the source text says, often to verbatim 
accuracy. Task answers and the source text thus have a reflexive relationship with each other so that what students 'find' in the source text has direct relevance on what they end up writing as a task answer, and the constructed formulation can in turn be checked for correctness against these 'findings'. Occasionally, the problem is a lack of 'findings', as in extract 2.

Besides the source text, formulations show sensitivity to task instructions. With the exception of the reading comprehension task in extract 2, in extracts analysed in this study students collaboratively complete quiz questions based on readings, which they will later present to other students in the class. Such an instruction can give rise to relatively particular local concerns that students need to attend to when writing to complete the task. Firstly, students are then required to formulate what are in grammatical terms questions, as opposed to 'answers', which written tasks involving separate readings typically target. Secondly, they may need to take care that they design their formulations to suit a particular audience, the other students (extract 4). Both requirements foreground the local contingencies that specific task instructions set for students' language use in the classroom.

In the light of analysed sequences, collaborative writing in the CLIL classroom is a distinctly bilingual phenomenon, one in which students use their L1 heavily for finding and making sense of 'content' in the source text as well as for negotiating and revising formulations. Besides the act of inscribing words on paper, L2 comes into play in the production of the actual formulation, at least in the present data, which shows students with fairly limited exposure to CLIL teaching (but see extract 4 that involves the use of L2 for all sub-activities). While this kind of a language alternation pattern may seem not to take full advantage of the opportunities for meaning-focused communication in the L2 that CLIL teaching aims to create, it also is quite typical 
student behaviour in bilingual educational contexts (see also Cromdal 2005; Bonacina and Gafaranga 2011). In that the alternation also marks a separation between the activities of establishing the 'content' and the linguistic formulation for a written answer (cf. 'question-answering' and 'question framing', Szymanski 2003), it also provides micro-analytical empirical evidence of the systematics behind the use of L1 and L2 resources in support of learning (see e.g. Cromdal 2005; Gierlinger 2015; Jakonen 2016b; Méndez García and Pavón Vázquez 2012).

The separation of content and language production in different activities also provides for the possibility that students may well 'know' the answer in their L1, in the sense that they can explain it, but cannot formulate it in L2 without the help of a peer or a teacher (extract 2 being a case in point). This is an observation that has implications for assessment in CLIL contexts, not only for researchers but also for practitioners. What is in fact being evaluated when students' proficiency and attainment in CLIL programmes is assessed (i.e., content, language or their integrated 'result') and what should the assessment target are questions that closely depend on understanding what language, content and their integration mean.

To conclude about the integration of content and language, students' negotiation for constructing task answer formulations is not merely work through which content gets neatly packaged into language. Rather, the interactional construction of formulations involves shifts back and forth between those two fundamental aspects of CLIL teaching, as well as an orientation to other local and contextual relevancies set by task work. Thus, students can revise answer formulations not only to get the grammar 'right', but also, as already mentioned, if they do not correctly reflect the content in the source text or otherwise fit the task. All in all, this study has demonstrated that content and language integration is visible in the minute details of interactional task work and in 
students' language use in bilingual settings. Further interactional studies are needed in order to specify the subtleties of integration as well as their relation to local contingencies and material resources of education. Doing this can offer substantial payoffs in the form of increased understanding of how content and language integration plays out in the everyday praxis of bilingual classrooms.

\section{Acknowledgements}

This research was funded by a postdoctoral grant from the Finnish Cultural Foundation. I would also like to express my gratitude to Tarja Nikula and two anonymous reviewers for their insightful and constructive comments to previous versions of this article. All remaining errors, omissions and shortcomings are mine.

\section{References}

Achugar, Mariana, and Brian D. Carpenter. 2014. "Tracking Movement toward Academic Language in Multilingual Classrooms." Journal of English for Academic Purposes 14: 60-71. doi:10.1016/j.jeap.2013.12.002.

Barwell, Richard. 2005a. "Integrating Language and Content: Issues from the Mathematics Classroom." Linguistics and Education 16 (2): 205-218. doi:10.1016/j.linged.2006.01.002.

Barwell, Richard. 2005b. "Critical Issues for Language and Content in Mainstream Classrooms: Introduction." Linguistics and Education 16 (2): 143-150. doi:10.1016/j.linged.2006.01.003.

Bonacina, Florence, and Joseph Gafaranga. 2011. “'Medium of Instruction’ vs. 'medium of Classroom Interaction': Language Choice in a French Complementary School Classroom in Scotland." International Journal of Bilingual Education and Bilingualism 14 (3): 319-334. doi:10.1080/13670050.2010.502222.

Cromdal, Jakob. 2005. "Bilingual Order in Collaborative Word Processing: On Creating an English Text in Swedish.” Journal of Pragmatics 37 (3): 329-353. doi:10.1016/j.pragma.2004.10.006. 
de la Colina, Ana Alegría, and Maria del Pilar García Mayo. 2007. "Attention to Form across Collaborative Tasks by Low-Proficiency Learners in an EFL Setting." In Investigating Tasks in Formal Language Learning, edited by Maria del Pilar García Mayo, 91-116. Clevedon: Multilingual Matters.

Drew, Paul. 1997. “'Open’ Class Repair Initiators in Response to Sequential Sources of Troubles in Conversation." Journal of Pragmatics 28 (1): 69-101. doi:10.1016/S0378-2166(97)89759-7.

Esquinca, Alberto. 2011. "Bilingual College Writers' Collaborative Writing of Word Problems." Linguistics and Education 22 (2): 150-167. doi:16/j.linged.2010.12.006.

Gajo, Laurent. 2007. "Linguistic Knowledge and Subject Knowledge: How Does Bilingualism Contribute to Subject Development?" International Journal Of Bilingual Education And Bilingualism 10 (5): 563-581. doi:10.2167/beb460.0.

Gierlinger, Erwin. 2015. “'You Can Speak German, Sir”: On the Complexity of Teachers' L1 Use in CLIL." Language and Education 29 (4): 347-368. doi:10.1080/09500782.2015.1023733.

Hornberger, Nancy H., and Ellen Skilton-Sylvester. 2000. "Revisiting the Continua of Biliteracy: International and Critical Perspectives." Language and Education 14 (2): 96-122. doi:10.1080/09500780008666781.

Jakonen, Teppo. 2015. "Handling knowledge: using classroom materials to construct and interpret information requests." Journal of Pragmatics 89: 100-112. doi:10.1016/j.pragma.2015.10.001

Jakonen, Teppo. 2016a. "Gaining access to another participant's writing in the classroom.” Language and Dialogue 6 (1): 179-204. doi:10.1075/ld.6.1.06jak

Jakonen, Teppo. 2016b. "Managing multiple normativities in classroom interaction: Student responses to teacher reproaches for inappropriate language choice in a bilingual classroom." Linguistics and Education 33: 14-27. doi:10.1016/j.linged.2015.11.003

Jefferson, Gail. 2004. “Glossary of Transcript Symbols with an Introduction.” In Conversation Analysis: Studies from the First Generation, edited by Gene H. Lerner, 13-31. Philadelphia, PA: John Benjamins. 
Kääntä, Leila. 2014. “From Noticing to Initiating Correction: Students’ Epistemic Displays in Instructional Interaction." Journal of Pragmatics 66: 86-105. doi:10.1016/j.pragma.2014.02.010.

Kim, YouJin. 2009. "The Effects of Task Complexity on Learner-Learner Interaction." System 37 (2): 254-268. doi:10.1016/j.system.2009.02.003.

Kunitz, Silvia. 2015. "Scriptlines as Emergent Artifacts in Collaborative Group Planning.” Journal of Pragmatics 76: 135-149. doi:10.1016/j.pragma.2014.10.012.

Laakso, Minna, and Marja-Leena Sorjonen. 2010. “Cut-off or Particle-Devices for Initiating Self-Repair in Conversation." Journal of Pragmatics 42: 1151-1172. doi:10.1016/j.pragma.2009.09.004.

Lerner, Gene H. 1995. "Turn Design and the Organization of Participation in Instructional Activities.” Discourse Processes 19: 111-131. doi:10.1080/01638539109544907.

Llinares, Ana. 2015. "Integration in CLIL: A Proposal to Inform Research and Successful Pedagogy." Language, Culture and Curriculum 28 (1): 58-73. doi:10.1080/07908318.2014.1000925.

Loewen, Shawn. 2011. "Focus on Form." In Handbook of Research in Second Language Teaching and Learning, Volume II, edited by Eli Hinkel, 576-592. New York: Routledge.

Lyster, Roy. 2007. Learning and Teaching Languages through Content: A Counterbalanced Approach. Amsterdam: John Benjamins.

Méndez García, María Del Carmen, and Víctor Pavón Vázquez. 2012. "Investigating the Coexistence of the Mother Tongue and the Foreign Language through Teacher Collaboration in CLIL Contexts: Perceptions and Practice of the Teachers Involved in the Plurilingual Programme in Andalusia.” International Journal of Bilingual Education and Bilingualism 15 (5): 573-592. doi:10.1080/13670050.2012.670195.

Meyer, Oliver, Do Coyle, Ana Halbach, Kevin Schuck, and Teresa Ting. 2015. “A Pluriliteracies Approach to Content and Language Integrated Learning - Mapping Learner Progressions in Knowledge Construction and Meaning-Making." Language, Culture and Curriculum 28 (1): 41-57. doi:10.1080/07908318.2014.1000924. 
Mondada, Lorenza, and Kimmo Svinhufvud. 2016. "Writing-in-Interaction: Studying Writing as a Multimodal Phenomenon in Social Interaction." Language and Dialogue 6 (1): 1-53.

Nassaji, Hossein, and Sandra Fotos. 2011. Teaching Grammar in Second Language Classrooms: Integrating Form-Focused Instruction in Communicative Context. Abingdon, Oxon: Routledge.

Nikula, Tarja. 2012. "On the Role of Peer Discussions in the Learning of SubjectSpecific Language Use in CLIL." In Discourse and Language Learning across L2 Instructional Settings, edited by Eva Alcón-Soler and M.P. Safont-Jordá, 133-153. Amsterdam: Rodopi.

Nikula, Tarja, Emma Dafouz, Pat Moore, and Ute Smit, eds. 2016. Conceptualising Integration in CLIL and Multilingual Education. Bristol: Multilingual Matters.

Nikula, Tarja, Christiane Dalton-Puffer, Ana Llinares, and Francisco Lorenzo. 2016. "More than Content and Language: The Complexity of Integration in CLIL and Multilingual Education.” In Conceptualising Integration in CLIL and Multilingual Education, edited by Tarja Nikula, Emma Dafouz, Pat Moore, and Ute Smit. Bristol: Multilingual Matters.

Schleppegrell, Mary J. 2004. The Language of Schooling: A Functional Linguistics Perspective. Journal of Chemical Information and Modeling. Mahwah (NJ): Lawrence Erlbaum.

Schleppegrell, Mary J, and Catherine L. O’Hallaron. 2011. “Teaching Academic Language in L2 Secondary Settings." Annual Review of Applied Linguistics 31: 3 18. doi:10.1017/S0267190511000067.

Shanahan, Timothy, and Cynthia Shanahan. 2008. "Teaching Disciplinary Literacy to Area Literacy." Harvard Educational Review 78 (1): 40-60.

Sidnell, Jack, and Tanya Stivers, eds. 2012. The Handbook of Conversation Analysis. Oxford: Wiley-Blackwell.

Storch, Neomy. 1997. "The Editing Talk of Adult ESL Learners." Language Awareness 6 (4): 221-232. doi:10.1080/09658416.1997.9959931.

Storch, Neomy. 2011. "Collaborative Writing in L2 Contexts: Processes, Outcomes, and Future Directions.” Annual Review of Applied Linguistics 31: 275-288. 
doi:10.1017/S0267190511000079.

Swain, Merrill. 2006. "Languaging, Agency and Collaboration in Advanced Second Language Proficiency." In Advanced Language Learning: The Contribution of Halliday and Vygotsky, edited by Heidi Byrnes, 95-108. London: Continuum.

Szymanski, Margaret H. 2003. "Producing Text through Talk: Question-Answering Activity in Classroom Peer Groups." Linguistics and Education 13 (4): 533-563. doi:10.1016/S0898-5898(03)00003-2.

ten Have, Paul. 2007. Doing Conversation Analysis: A Practical Guide. Introducing Qualitive Methods. 2nd ed. London: Sage. 